\title{
Pharmacokinetics and antibacterial activity of daily gentamicin
}

\author{
H Skopnik, R Wallraf, B Nies, K Tröster, G Heimann
}

\begin{abstract}
Twenty full term neonates with suspected bacterial infection were randomly assigned to a once daily or a twice daily dosage regimen with gentamicin ( $4 \mathrm{mg} / \mathrm{kg} /$ day). Concomitantly all patients were treated with ampicillin (200 $\mathrm{mg} / \mathrm{kg} / \mathrm{day}$ ). The gentamicin concentration time curves were analysed by an open two compartment model under steady state conditions on day 4 of treatment. The mean theoretical maximum serum concentration in the group taking gentamicin once daily (10.9 $\mu \mathrm{g} / \mathrm{ml}$ ) was significantly higher than in the group taking it twice daily $(7 \cdot 4 \mu \mathrm{g} / \mathrm{ml})$. Potentially toxic serum concentrations were never reached. Mean trough concentrations were comparable in both groups (once daily 0.8 $\mu \mathrm{g} / \mathrm{ml}$; twice daily $1.0 \mu \mathrm{g} / \mathrm{ml}$ ). Urinary alanine aminopeptidase excretion increased during and even two days after end of treatment in both groups without any significant differences.

The results of the dynamic in vitro model revealed that both dosage schedules showed comparable bactericidal effects on pathogens inhibited by low concentrations of gentamicin like Escherichia coli and Staphylococcus aureus. However the once daily regimen was significantly superior in isolates with high minimal inhibitory concentrations.
\end{abstract}

The combination of gentamicin, as a representative of aminoglycoside antibiotics, with $\beta$ lactam antibiotics is widely used. It has been proved as an effective antibiotic strategy in neonates with suspected or documented bacterial infection. Gentamicin, like all other aminoglycosides, exhibits a narrow range between toxic and therapeutic dosages. It is generally accepted that peak concentrations $>4 \mu \mathrm{g} / \mathrm{ml}$ are necessary for antibacterial efficiency and that trough concentrations of $>2 \mu \mathrm{g} / \mathrm{ml}$ are a risk factor for nephrotoxicity and ototoxicity. ${ }^{1-3}$ It has been shown that the bactericidal activity of aminoglycosides is dependent on plasma concentrations and that higher peak concentrations are associated with improved therapeutic response in life threatening bacterial infection. ${ }^{12}$

Furthermore, aminoglycosides exhibit a postantibiotic effect that correlates with the extent of peak concentration above the minimal inhibitory concentration for the infecting organism. ${ }^{4}$ These data and results of preliminary studies concerning aminoglycoside associated nephrotoxicity and ototoxicity provide support for a once daily aminoglycoside dosing schedule. ${ }^{156}$ Because elimination half lifes of aminoglycosides are longer in neonates than in older children and adults the daily single dose regimen might be a less toxic and more effective approach in this age group. ${ }^{6-10}$

The aims of this study were the evaluation of pharmacokinetic profiles of gentamicin in neonates in once and twice daily dosage regimens, the determination of antibacterial properties of these profiles in a dynamic in vitro model, and finally the influence of the dosing regimens on urinary excretion of alanine aminopeptidase. Alanine aminopeptidase is a brush border associated enzyme of the proximal renal tubules and acts as a marker of preclinical nephrotoxicity. 511

\section{Patients and methods}

Twenty neonates with pneumonia $(n=7)$, meconium aspiration $(n=2)$, suspected bacterial infection indicated by $\mathrm{C}$ reactive protein concentration $>8 \mathrm{mg} / \mathrm{l}(\mathrm{n}=4)$ and premature rupture of membranes $>36$ hours before delivery $(n=7)$ were studied. They were included in the study on the first to third postnatal day after obtaining informed parental consent. Patients with a gestational age $<37$ weeks, Apgar scores $\leqslant 4$ ( 1 min) and $\leqslant 6(5 \mathrm{~min})$, birth weight $<2500 \mathrm{~g}$, serum creatinine concentrations $>85 \mu \mathrm{mol} / 1$, and those who required diuretics during the course of treatment as well as those who were exposed to aminoglycosides prenatally were excluded from the study.

The babies were randomly assigned to a once daily (GM I; $4 \mathrm{mg} / \mathrm{kg}$ ) and twice daily (GM II; $2 \times 2 \mathrm{mg} / \mathrm{kg}$ ) dosage regimen with gentamicin. All patients were concomitantly treated with ampicillin $(200 \mathrm{mg} / \mathrm{kg} /$ day $)$. Characteristics of the study population are shown in table 1 .

Gentamicin was administered over 30 minutes using a syringe pump. The pharmacokinetic profile of gentamicin in serum was determined on the fourth day of treatment. Blood samples $(0.4 \mathrm{ml})$ were obtained from a venous catheter, $1,4,6,12$, and 24 (GM I only) hours after starting the infusion. The serum concentration of gentamicin was measured with a fluorescence

Table 1 Characteristics of study population

\begin{tabular}{lll}
\hline & $G M I$ & $G M I I$ \\
\hline No of patients & 10 & 10 \\
Male/female & $3 / 7$ & $5 / 5$ \\
Gestational age (weeks) & $39 \cdot 5(1 \cdot 4)$ & $40 \cdot 3(0 \cdot 8)$ \\
Age (days) & $1 \cdot 3(1 \cdot 1)$ & $0 \cdot 7(0 \cdot 7)$ \\
Weight (kg) & $3 \cdot 3(0 \cdot 6)$ & $3 \cdot 8(0 \cdot 6)$ \\
Serum creatinine ( $\mu \mathrm{mol} / \mathrm{l})$ & $67(12)$ & $61(14)$ \\
Duration of treatment (days) & $9(1 \cdot 7)$ & $8(1 \cdot 7)$ \\
\hline
\end{tabular}

Results are mean (SD).

\footnotetext{
Dr Skopnik.

Accepted 1 August 1991

RWTH Aachen,

D-5100

of Germany

R Wallraf

E Merck Company, Darmstadt

B Nies

K Trö̈ter
} 
polarisation immunoassay $\left(\mathrm{TD}_{\mathrm{x}}-\right.$ System, Abbott) immediately after sample collection.

Serum concentration time curves of gentamicin were fitted using the Rotating Iterative Procedure program with the assumption of an open two compartment model. ${ }^{12}$ Areas under the concentration time profiles (AUC) for gentamicin concentrations $>4 \mu \mathrm{g} / \mathrm{ml}$ were calculated by the trapezoidal method. Pharmacokinetic parameters such as theoretical maximal concentrations and AUC for 24 hours derived from curve fitting to a two compartment model.

Urine was sampled for three hours between 6 am and 9 am using a urine collection bag on the second, fourth, and sixth day of treatment, and two days after gentamicin treatment was discontinued. Traces of sodium azide as a preservative were added to urine samples which were stored at $4^{\circ} \mathrm{C}$ for a maximum of 48 hours. After gel filtration (Sephadex column G25 PD10) the activity of alanine aminopeptidase was determined photometrically (405 $\mathrm{nm}$ ) using L-alanine-p-nitroanilide as the substrate with a method described by Mondorf et al. ${ }^{11}$ Urine concentrations of creatinine were assayed with a

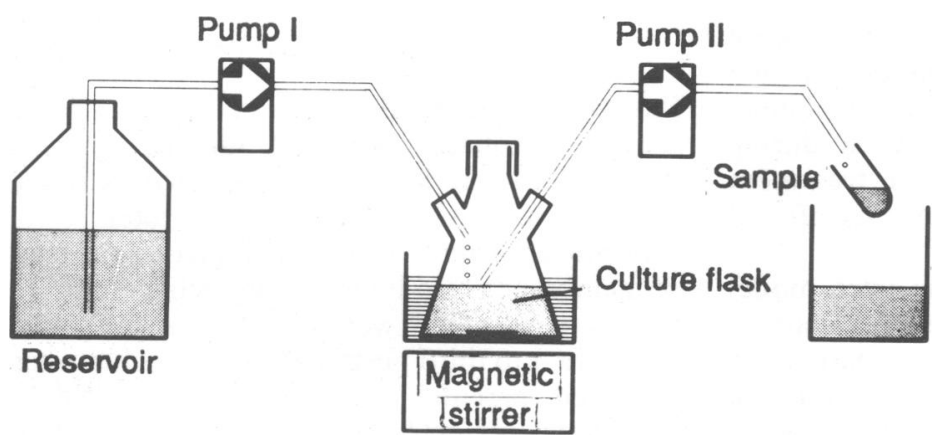

Figure 1 Schematic drawing of the applied in vitro model (for explanation of concentration adjustment see text). Pump II was run at about five times the flow rate of pump I, thus drawing filtered air into the culture flask to avoid anaerobic conditions. Volume constancy in the culture flask was provided by setting the outflow tube to a fixed level.

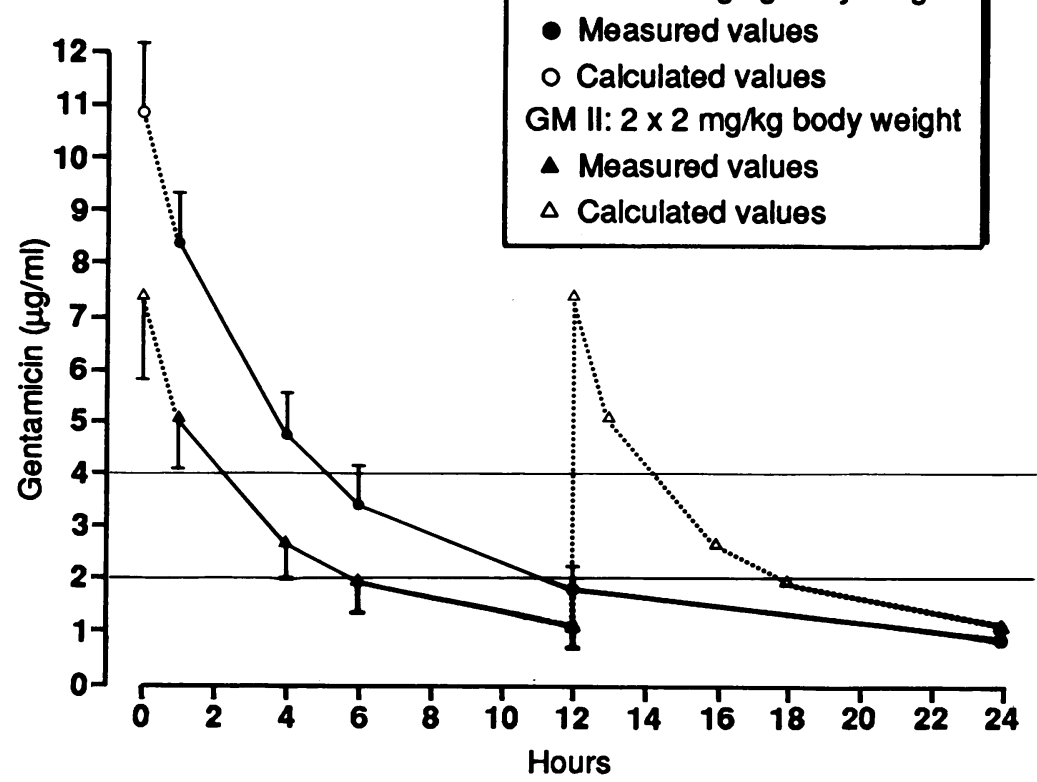

Figure 2 Mean $(S D)$ serum concentration time curves of gentamicin. modified method described by Popper et al. ${ }^{13}$ Alanine aminopeptidase activities were related to urinary creatinine concentrations and were corrected for body surface areas.

Statistical analysis was performed by Fisher's permutation test.

IN VITRO MODEL

The antibacterial activity of the mean serum gentamicin concentrations obtained with both dosing regimens was analysed in an in vitro model according to Grasso et al (fig 1). ${ }^{14}$ Due to the non-log linear serum concentration time curve gentamicin kinetics in the culture bottle of the in vitro model were simulated by an hourly adjustment of the pumping velocity. The exact necessary adjustment was determined empirically in provisional experiments. Gentamicin concentrations were determined by microbioassay using Bacillus subtilis ATCC 6633 as indicator strain at the time points indicated.

Growth medium in all experiments was standard I broth (E Merck). Test strains were the standard strains Staphylococcus aureus ATCC 25923, Escherichia coli ATCC, 25933, Pseudomonas aeruginosa ATCC 27853, and the clinical isolates Listeria monocytogenes OM 189 (gentamicin minimal inhibitory concentration $2 \mu \mathrm{g} / \mathrm{ml}$ ) and Enterococcus faecalis OM 25 (gentamicin minimal inhibitory concentration $4 \mu \mathrm{g} / \mathrm{ml}$ ). The inoculum size was set to approximately $1 \times 10^{6}$ colony forming units (cfu) by diluting a static over night culture 1: 500 for $E$ coli, $S$ aureus, and $P$ aeruginosa and 1:250 for $E$ faecalis, and $L$ monocytogenes.

\section{Results}

\section{PHARMACOKINETIC DATA}

The theoretical concentration $\left(\mathrm{C}_{\mathrm{o}}\right)$ of gentamicin in serum derives from extrapolation of the concentration time plot to time zero (figs 2 and 3). Values for $C_{o}$ ranged from 8.5 to $13.0 \mu \mathrm{g} / \mathrm{ml}$ in group GM I and from 5.2 to $10.1 \mu \mathrm{g} / \mathrm{ml}$ in group GM II. The measured peak serum concentraion $\left(C_{\max }\right)$ never exceeded the potentially

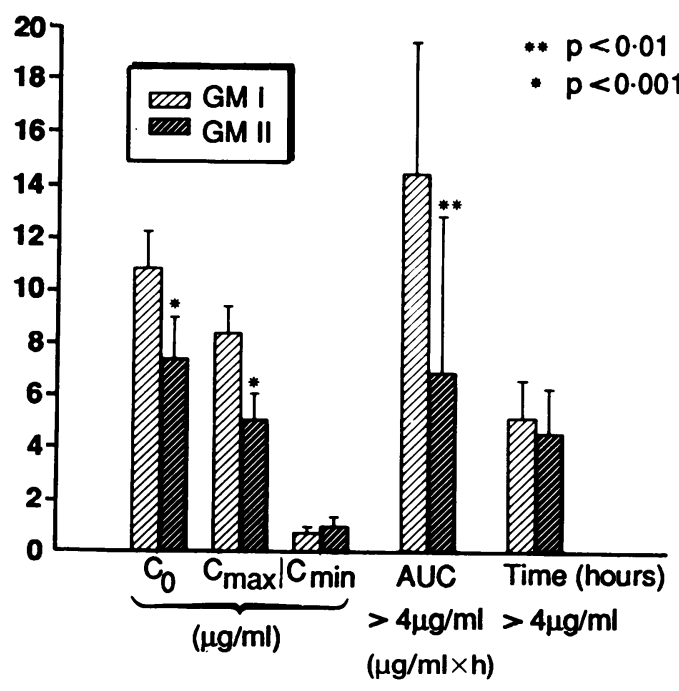

Figure 3 Mean (SD) pharmacokinetic parameters of gentamicin in neonates. 


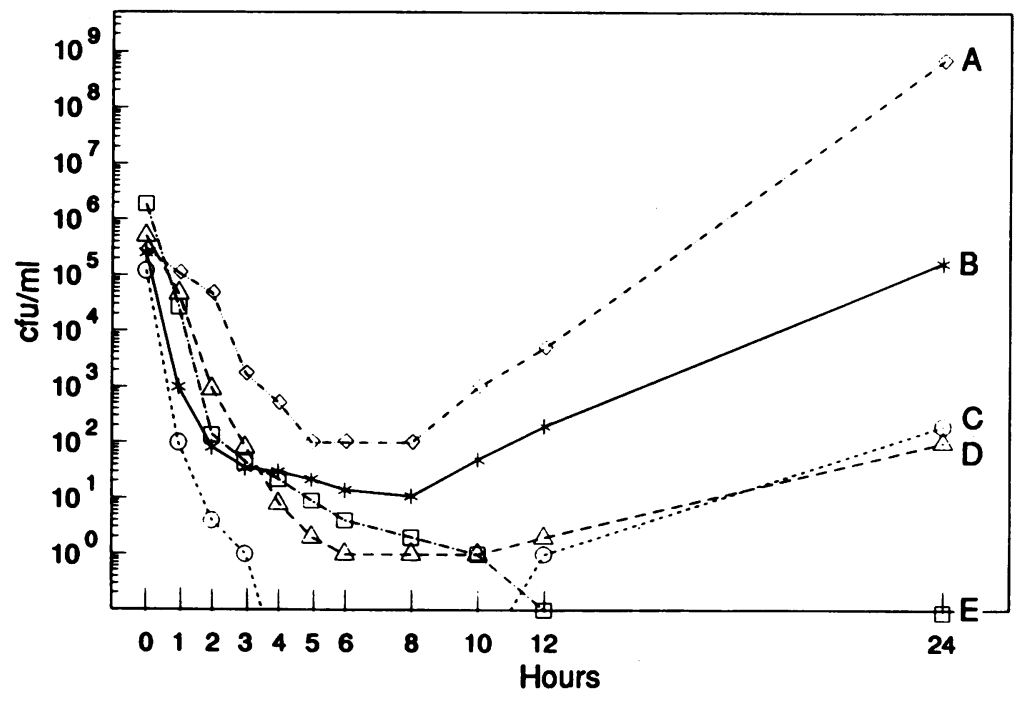

Figure 4 Bactericidal activity of gentamicin in the in vitro model obtained after simulating GM I pharmacokinetics. (A) Enterococcus faecalis OM 25, (B) Pseudomonas aeruginosa, ATCC 27853 , (C) Escherichia coli ATCC 25 922, (D) Staphylococcus aureus ATCC $25923,(E)$ Listeria monocytogenes OM 189.

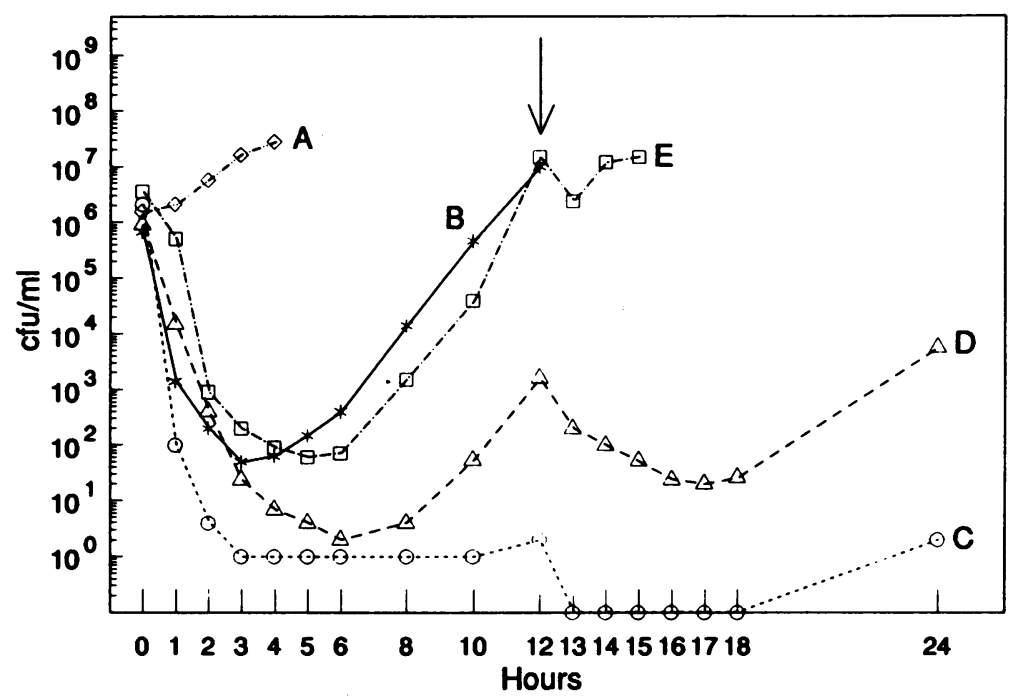

Figure 5 Bactericidal activity of gentamicin in the in vitro model obtained after simulating GM II pharmacokinetics. (A) Enterococcus faecalis OM $25,(B)$ Pseudomonas aeruginosa, ATCC 27 853, (C) Escherichia coli ATCC 25 922, (D) Staphylococcus aureus ATCC 25 923, (E) Listeria monocytogenes OM 189. Arrow indicates second dose.
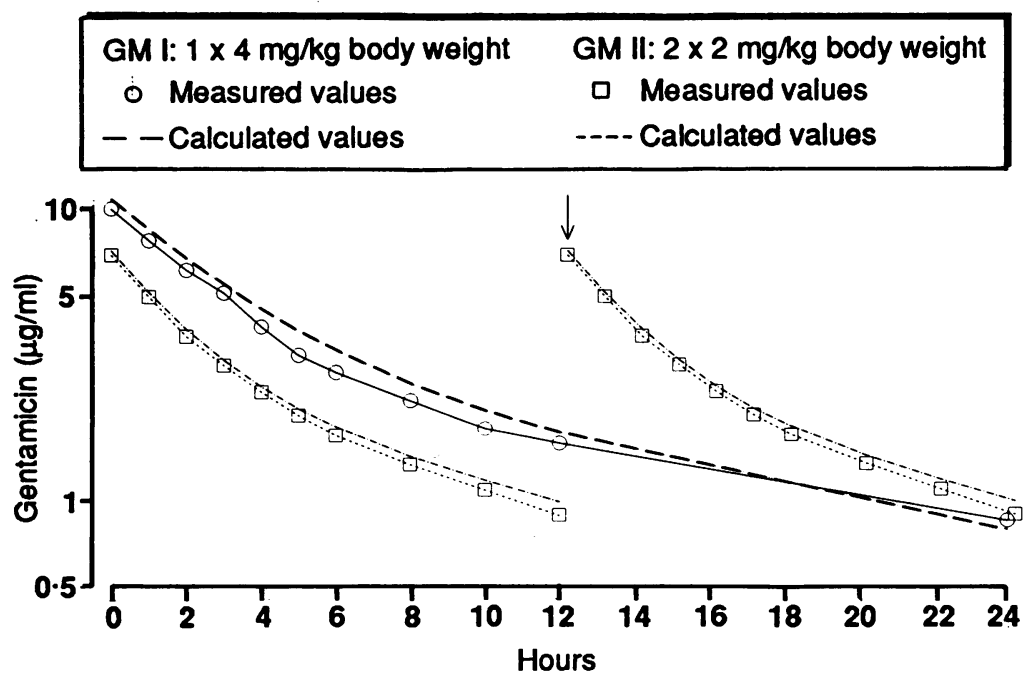

Figure 6 Comparison of gentamicin concentrations calculated from the mean pharmacokinetic parameters obtained from the patients and the concentrations determined in the in vitro mode. Arrow indicates second dose. toxic concentration of $12 \mu \mathrm{g} / \mathrm{ml}$ (figs 2 and 3). They ranged from $7 \cdot 0$ to $9 \cdot 9 \mu \mathrm{g} / \mathrm{ml}$ and from $4 \cdot 1$ to $7.7 \mu \mathrm{g} / \mathrm{ml}$ in group GM I and GM II, respectively.

Both $\mathrm{C}_{\mathrm{o}}$ and $\mathrm{C}_{\max }$ were significantly higher in the once daily group whereas the trough concentrations $\left(C_{\min }\right)$, which ranged from $0 \cdot 5-1 \cdot 2$ $\mu \mathrm{g} / \mathrm{ml}($ mean $(\mathrm{SD}) \mathrm{GM} \mathrm{I}: 0.8(0.2) \mu \mathrm{g} / \mathrm{ml})$ and from $0.5-1.7 \mu \mathrm{g} / \mathrm{ml}(\mathrm{GM}$ II: $1.0(0.4) \mu \mathrm{g} / \mathrm{ml}$ ), showed no significant differences $(p>0 \cdot 1)$ between the dosage schedules. The areas under the concentration time curves $\left(\mathrm{AUC}_{0-24}\right)$ were in comparable ranges in both treatment groups (mean (SD) GM I: $63.27(10 \cdot 6) \mu \mathrm{g} / \mathrm{ml} \times \mathrm{h} ; \mathrm{GM}$ II: $50.90(8.5) \mu \mathrm{g} / \mathrm{ml} \times \mathrm{h} ; \mathrm{p}>0.02)$. AUC for gentamicin concentrations $>4 \mu \mathrm{g} / \mathrm{ml}$ ranged from $9 \cdot 7$ to $24 \cdot 7 \mu \mathrm{g} / \mathrm{ml} \times \mathrm{h}$ (mean (SD) GM I: $14.5(5.0) \mu \mathrm{g} / \mathrm{ml} \times \mathrm{h}$ ) and from 1.3 to 22.8 $\mu \mathrm{g} / \mathrm{ml} \times \mathrm{h}(\mathrm{GM}$ II: $6.9(6.0) \mu \mathrm{g} / \mathrm{ml} \times \mathrm{h})$. They were significantly higher in group GM I $(p<0.01)$. The time periods $/ 24$ hours in which the concentrations of gentamicin exceeded $4 \mu \mathrm{g} / \mathrm{ml}$ were in comparable ranges in both groups (fig 3).

ALANINE AMINOPEPTIDASE URINARY EXCRETION Alanine aminopeptidase excretion increased in both treatment groups in the same pattern during and even after discontinuation of gentamicin therapy (table 2). Significant differences were not detectable between the groups at any time.

IN VITRO MODEL

Figures 4 and 5 show the results of the in vitro model experiments obtained after simulating the mean gentamicin serum concentration curves for GM I and GM II. The initial gentamicin concentrations were set to $10 \cdot 7$ $\mu \mathrm{g} / \mathrm{ml}$ in the GM I model and to $7 \cdot 2 \mu \mathrm{g} / \mathrm{ml}$ in the GM II model. In the GM I model gentamicin concentrations decreased slightly faster than calculated from the pharmacokinetic data, whereas in the GM II model there was a good correlation to the calculated values (fig 6).

In the GM I model all strains tested responded to the high initial concentrations of gentamicin by a rapid decrease of viable cell counts (fig 4). Significant regrowth was seen in the cultures of $E$ faecalis, $P$ aeruginosa, and $E$ coli starting after eight to 10 hours. For $P$ aeruginosa and $E$ coli the 24 hour cfu counts remained below the value for time zero.

In the GM II model (fig 6) all strains but $E$ faecalis were rapidly decreased in cfu counts. Significant regrowth started for $L$ monocytogenes, $S$ aureus, and $P$ aeruginosa after four to six hours and the value for time zero was reached within

Table 2 Mean (SD) urinary alanine aminopeptidase excretion durng and after treatment with gentamicin. Alanine aminopeptidase activities were related to urinary creatinine concentrations and were corrected for body surface areas $\left(U / \mathrm{mmol} / \mathrm{m}^{2}\right)$

\begin{tabular}{lll}
\hline & $G M I$ & $G M I I$ \\
\hline During treatment & $27 \cdot 8(23 \cdot 6)$ & $29 \cdot 1(16 \cdot 6)$ \\
Day 2 & $46 \cdot 1(34 \cdot 1)$ & $35 \cdot 7(22 \cdot 2)$ \\
Day 4 & $47 \cdot 1(30 \cdot 6)$ & $44 \cdot 1(13 \cdot 8)$ \\
Day 6 & $50 \cdot 5(14 \cdot 6)$ & $58 \cdot 7(23 \cdot 9)$ \\
After treatment & & \\
Day 2 & & \\
\hline
\end{tabular}


12 hours (before the second dosing). The second dose added to the culture resulted in a decrease of cfu counts for $S$ aureus with regrowth again starting after about six hours. On $L$ monocytogenes the second dose had a small influence only and no reduction in growth was seen for the $P$ aeruginosa strain.

\section{Discussion}

Pharmacokinetic data of gentamicin indicate that elimination half lives are longer in neonates especially in preterm infants compared with older children. ${ }^{7-10}$ Routine drug monitoring in neonates receiving intravenous gentamicin on a twice daily dosage schedule reveals that especially in preterm infants trough concentrations often exceed the potential toxic concentrations of $>2 \mu \mathrm{g} / \mathrm{ml}$ which are not accompanied by raised peak serum concentrations. ${ }^{15}$ These data lend support for the recommendation to increase the dosing interval from 12 to $18-24$ hours. ${ }^{19} 1617$ All our patients show gentamicin serum concentrations in the therapeutic range; potentially toxic trough and peak $(>12 \mu \mathrm{g} / \mathrm{ml})$ concentrations ${ }^{18}$ are not recorded under steady state conditions in this study. Determinants which might alter gentamicin elimination such as asphyxia, impaired renal function, and concomitant diuretic treatment are excluded. ${ }^{10} 19$

Recent studies have shown that therapeutic efficacy of aminoglycosides depends on peak concentrations and the AUC above the minimal inhibitory concentration of the infecting organism rather than duration of time serum concentrations exceed the minimal inhibitory concentration. ${ }^{20}$ The results obtained with the in vitro model of Grasso et al strongly underline that high peak concentrations of gentamicin are the main determinant for antibacterial activity. ${ }^{14}$ Most clearly this can be seen with the $E$ faecalis strain, which is strongly reduced in the GM I model and uninfluenced in the GM II model. In both treatment groups the duration of time for gentamicin concentrations $>4 \mu \mathrm{g} / \mathrm{ml}$ and the total AUC are in comparable ranges whereas the AUC above the level of $4 \mu \mathrm{g} / \mathrm{ml}$ is significantly higher in the once daily dosing group.

Although a postantibiotic effect is demonstrated for aminoglycosides, a reduction of dosing frequency might bear the risk of bacterial regrowth, especially if the dosing interval is longer than the duration of time of serum concentrations above the minimal inhibitory concentration plus the postantibiotic effect. This risk factor can obviously be balanced by the observation that the postantibiotic effect of gentamicin and its duration correlates with peak concentrations in serum and AUC above the minimal inhibitory concentration of the infecting organism and the fact that the elimination half life of gentamicin is longer in neonates than in older children. ${ }^{4}$

The mechanism of drug induced renal toxicity is the same for all aminoglycosides. After glomerular filtration a small fraction of aminoglycosides is reabsorbed in the proximal renal tubular cells by endocytosis. ${ }^{21}$ Aminoglycoside nephrotoxicity is caused by inhibition of lysosomal phospholipase and sphingomyelinase of the proximal tubular cells resulting in phospholipidosis of the lysosomes and formation of myeloid bodies. ${ }^{21} 22$ This leads to the loss of membrane integrity and finally to tubular necrosis. ${ }^{23}$ The risk of aminoglycoside induced toxicity is a function of cortical aminoglycoside concentration. ${ }^{1}$ As cortical uptake of aminoglycoside shows at least for gentamicin a pattern of saturable kinetics it is evident that different dosing regimens can affect the cortical accumulation of gentamicin. ${ }^{121}$ This assumption is validated by the results of a study where patients received the same dose of gentamicin either as a continuous infusion or as a single injection before nephrectomy. ${ }^{24}$ Renal gentamicin concentrations were significantly lower in the latter group.

After continuous infusion of gentamicin significantly lower creatinine clearance and excretion of $\beta_{2}$-microglobulin are found in neonates than after a twice daily dose regimen. ${ }^{25}$

The excretion of alanine aminopeptidase a brush border associated enzyme of the proximal renal tubules into the urine is a sensitive parameter of preclinical gentamicin nephrotoxicity. ${ }^{15} 1126$ Gentamicin induced enzymuria is lower in neonates than in adults; this is in accordance with clinical studies that renal toxicity is less frequent in newborns. ${ }^{7} 27$ The latter can be explained by a lower rate of renal gentamicin accumulation in the neonate. ${ }^{7}$ The patterns of alanine aminopeptidase excretion are similar in both treatment groups; this is in contrast to a study in healthy volunteers where more pronounced enzymuria was recorded on a twice daily dosage regimen. ${ }^{5}$

Contrary to nephrotoxicity the mechanism of ototoxicity of aminoglycosides remains to be determined. Several risk factors such as duration of treatment, total dose, the AUC, and impaired renal function are identified.

Another study reported that patients with auditory toxicity who underwent treatment for a longer period were more likely to be bacteraemic and had, on average, a higher temperature ${ }^{28}$ Experimental studies give some evidence that less frequent dosage regimens cause less ototoxicity. ${ }^{1}$ Summarising the recent data on aminoglycoside toxicity there is some evidence that raised trough rather than peak serum concentrations are the main determinant of both nephrotoxicity and ototoxicity.

In conclusion, the results of this study indicate that the once daily dosage regimen of gentamicin in term infants guarantees peak serum concentrations above the minimal inhibitory concentration of bacteria, which are relevant in the neonatal period, and trough concentrations below the potentially toxic concentration of $2 \mu \mathrm{g} / \mathrm{ml}$. From the results of the dynamic in vitro model it can be concluded that the single daily dose administration is superior to the twice a day regimen. As alanine aminopeptidase release from the proximal tubular cells into the urine as a sensitive marker of preclinical renal toxicity is similar in both dosing schedules, an increased risk for nephrotoxicity is unlikely to occur on a once daily regimen. Whether this approach of larger less frequent doses provides similar advantages in 
preterm infants where dosage intervals are already considerably extended remains to be investigated.

1 Mattie H, Craig WA, Pechère JD. Determinants of efficacy and toxicity of aminoglycosides. F Antimicrob Chemother and toxicity of

2 Moore RD, Lietman PS, Smith CR. Clinical response to aminoglycoside therapy: importance of the ratio of peak concentration to minimal inhibitory concentration. $\mathcal{F}$ Infect Dis 1987;155:93-9.

3 Siber GR, Echeverria P, Smith AL, Paisley JW, Smith DH. Pharmacokinetics of gentamicin in children and adults. $\mathcal{F}$ Infect Dis 1975;132:637-51.

4 Craig WA, Gudmundsson S. The postantibiotic effect. In: Lorian V, ed. Antibiotics in laboratory medicine. 2nd Ed. Baltimore: Williams and Wilkins, 1986:515-36.

5 Mondorf AW, Jakob H, Jelinek C, Scherberich JE, Hess $H$, Schoeppe W. Enzymuria as a marker of drug-induced nephrotoxicity. In: Fillastre J-P, ed. Nephrotoxicity, ototoxicity of druss. Rollen: Editions Inserm Publications de l'Université de Rouen, 1982:167-78.

6 Skopnik H, Wallraf R, Nies BA, Heimann G. Pharmacokinetics, toxicity and antimicrobial activity of gentamicin in netics, toxicity and antimicrobial activity of gent $\mathcal{F}$ Pediatr 1990;149:373.

7 Heimann G. Renal toxicity of aminoglycosides in the neonatal period. Pediatric Pharmacology 1983;3:251-7.

8 Herod. Pediatric Pharmacology 1983;3:251-7. Win E, French JN. Pharmacokinetics of gentamicin in very low birth JN. Pharmacokinetics of gentamicin in very low birth weight pre

9 McCracken GH, Jones LG. Gentamicin in the neonatal period. Am $\mathcal{F}$ Dis Child 1970;120:524-33.

10 Pons G, d'Athis P, de Lauture D, Richard MO, Badoual J, Olive G. Gentamicin monitoring in neonates. Ther Drug Monit 1988;10:421-7.

11 Mondorf AW, Breier J, Hendus J, et al. Effect of aminoglycosides on proximal tubular membranes of the human kidney. Eur 7 Clin Pharmacol 1978;13:133-42.

12 Hattingberg von HM, Brockmeier D, Kreuter G. A rotating iterative procedure (RIP) for estimating hybrid constants in multi-compartment analysis on desk computers. Eur 7 Clin Pharmacol 1977;11:381-8.

13 Popper H, Mandel E, Mayer H. Zur Kreatininbestimmung im Blute. Biochemische Zeitschrift 1937;291:354-67.
14 Grasso S, Meinardi RD, De Carneri I, Tamassai V. New in vitro model to study the effect of antibiotic concentration and rate of elimination on antibacterial activity. Antimicrob Agents Chemother 1978;13:570-6.

15 Mulhall A, de Louvois J, Hurley R. Incidence of potentially toxic concentrations of gentamicin in the neonate. Arch Dis Child 1983;58:897-900.

16 Edwards C, Low DC, Bissenden JG. Gentamicin dosage for the newborn. Lancet 1986;i:508-9.

17 Sommer R, Eitelberger F, Hohenauer L. GentamicinDosierung beim Neugeborenen. Klin Pädiatr 1989;201: 387-92.

18 McCracken GH, Threlkeld N, Thomas ML. Intravenous administration of kanamycin and gentamicin in newborn administration of kanamycin and

19 Whelton A. Therapeutic initiatives for the avoidance of aminoglycoside toxicity. F Clin Pharmacol 1985;25:67-81.

20 Leggett JE, Fantin B, Ebert S, et al. Comparative antibiotic dose-effect relations at several dosing intervals in murine pneumonitis and thigh-infection models. F Infect Dis 1989;159:281-92.

21 De Broe ME, Guiliano RA, Verpooten GA. Choice of drug and dosage regimen. Two important risk factors for aminoglycoside nephrotoxicity. Am $\mathcal{F}$ Med 1986;80(suppl 6 B):115-8.

22 Ghosh P, Chatteriee S. Effects of gentamicin on sphingomyelinase activity in cultured human renal proximal tubulus cells. F Biol Chem 1987;262:12550-6.

23 Wellwood JM, Lovell D, Thompson AE, Tighe JR. Renal damage caused by gentamicin: a study of the effects on renal morphology and urinary enzyme excretion. $\mathbf{f}$ Pathol renal morphology

24 Verpooten GA, Giuliano RA, Verbist L, Eestermans G, De Broe ME. Once daily dosing decreases renal accumulation of gen 22 .

25 Giacoia GP, Schentag JJ. Pharmacokinetics and nephrotoxicity of continous intravenous infusion of gentamicin in low birth weight infants. 7 Pediatr 1986;109:715-9.

26 Burchardt U, Hempel A, Höpfner JB, Hempel RD. Alaninaminopeptidase- und Kreatininausscheidung unter verschiedenen Diuresezuständen beim Menschen. $Z$ Gesamte Inn Med 1976;31:550-2.

$27 \mathrm{McCracken} \mathrm{GH}$. Aminoglykoside toxicity in infants and children. Am $\dot{F}$ Med 1986;80(suppl 6 B):172-8

28 Moore RD, Smith CR, Lietman PS. Risk factors for the development of auditory toxicity in patients receiving aminoglycosides. $\mathcal{F}$ Infect Dis 1984;149:23-30. 